This item was submitted to Loughborough's Research Repository by the author.

Items in Figshare are protected by copyright, with all rights reserved, unless otherwise indicated.

\title{
Failure analysis of a frangible composite cover: A transient-dynamics study
}

\section{PLEASE CITE THE PUBLISHED VERSION}

http://dx.doi.org/10.1177/0021998316673223

\section{PUBLISHER}

(c) The Authors. Published by SAGE Publications.

\section{VERSION}

AM (Accepted Manuscript)

\section{PUBLISHER STATEMENT}

This work is made available according to the conditions of the Creative Commons Attribution-NonCommercialNoDerivatives 4.0 International (CC BY-NC-ND 4.0) licence. Full details of this licence are available at: https://creativecommons.org/licenses/by-nc-nd/4.0/

\section{LICENCE}

CC BY-NC-ND 4.0

\section{REPOSITORY RECORD}

Cai, Deng'an, Guangming Zhou, Yuan Qian, and Vadim V. Silberschmidt. 2019. "Failure Analysis of a Frangible Composite Cover: A Transient-dynamics Study". figshare. https://hdl.handle.net/2134/24374. 


\title{
Failure analysis of a frangible composite cover:
}

\section{A transient-dynamics study}

\author{
Deng'an Cai', Guangming Zhou', Yuan Qian' \\ and Vadim V Silberschmidt ${ }^{3}$
}

\begin{abstract}
A transient-dynamics model based on the approximate Riemann algorithm is proposed for the failure analysis of a frangible composite canister cover. The frangible cover, manufactured with a traditional manual lay-up method, is designed to conduct a simulated missile launch test using a specially developed test device. Deformation of the cover's centre is determined using a transient-dynamics finite element model; failure pressure for the frangible cover is obtained based on a failure criterion and compared with simulated experimental results. Weak-zone position of the frangible cover has a significant effect on failure pressure compared to that of deformation of the cover's centre. With the same structure of the weak-zone, an increase in its height can first raise and then reduce the level of failure pressure of the frangible cover. Close agreements between the experimental and numerical results are observed.
\end{abstract}

\section{Keywords}

Composite material, frangible cover, transient-dynamics model, approximate Riemann algorithm, failure analysis

\section{Introduction}

As an important part of a missile storage and launch system, a missile-launch canister cover is a storage device of an inner missile to protect a warhead to avoid damage and to prevent a leak of inert gas before the missile is launched. In the process of missile launch, the cover should be opened timely, not affecting a normal launch. From the early seventies, many attempts have been made by various researchers to develop different metal missile launch canister covers, which were opened mechanically or burst. ${ }^{1-4}$ Major drawbacks of these metal canister covers are complexity of their mechanism, difficulty in manufacturing, ponderous structure, high cost, etc., that can directly affect stability of the covers. Therefore, there is a need to seek and study more reliable alternatives to these covers.

Thanks to good properties such as high strengthweight ratio, good corrosion resistance and long fatigue lives, composite materials are replacing metals in aerospace applications. Gradually, many canister covers of missile launch systems are manufactured with composite materials. For instance, Doane $e^{5}$ designed a bursting type of a composite film cover with a simple structure using glass/epoxy laminates. This cover could markedly improve a reaction speed of the launch system with a composite canister diaphragm designed, but a warhead might be damaged while bursting. With this consideration, Kam et al. $^{6}$ and $\mathrm{Wu}$ et al. $^{7}$ developed a frangible laminated composite canister cover, which would not cause any damage to the missile during its emission process. The cover would burst open in accordance with a predetermined pattern, allowing the missile to fly out of the canister unharmed when subjected to an internal impulsive pressure generated by the missile engine. A phenomenological Tsai-Wu failure criterion was used theoretically for strength prediction of the canister cover with a static finite element

\footnotetext{
'State Key Laboratory of Mechanics and Control of Mechanical Structures, Nanjing University of Aeronautics and Astronautics, Nanjing, P. R. China

${ }^{2}$ Purple Mountain Observatory, Chinese Academy of Sciences, Nanjing, P. R. China

${ }^{3}$ Wolfson School of Mechanical, Electrical and Manufacturing Engineering, Loughborough University, Leicestershire, UK
}

\section{Corresponding author:}

Guangming Zhou, State Key Laboratory of Mechanics and Control of Mechanical Structures, Nanjing University of Aeronautics and Astronautics, No. 29 Yudao Street, Nanjing 210016, P. R. China. Email: zhougm@nuaa.edu.cn 
(FE) model. The accuracy of the Tsai-Wu criterion in predicting first ply failure of laminated composite plates was verified in their previous studies. ${ }^{8-12}$ In our previous works, structures and properties of integrated frangible composite covers were investigated numerically and experimentally. ${ }^{13,14}$ The effect of a weak-zone structure on the performance of the frangible cover was discussed, and it was shown that the strength of the cover could be influenced primarily by the structural parameters of composite layers bonded on two sides of the weak-zone. Also, a failure analysis of a fly-through frangible canister cover was studied based on transient dynamics employing FE method. ${ }^{15}$ The obtained results showed that failure pressure and corresponding time rose as the length of bonding layer increased.

Although in theory, these works should give a significant improvement to our knowledge of properties of frangible composite canister covers, practically it was found that it is not an easy task to fully understand them using only static FE models. Due to complex material behavior and actual load conditions, the chosen type of analysis model can result in some differences in numerical results. In this regard, a transient-dynamics model (TDM) of a small-scale circular frangible composite canister cover made of laminated composite materials is presented here. The model based on the approximate Riemann solver ${ }^{16-18}$ is developed and used to analyse the burst process and failure pressure of the cover. Additionally, experimental studies of deformation and burst strength of frangible composite cover were performed in the simulated launch setup to validate the numerical results.

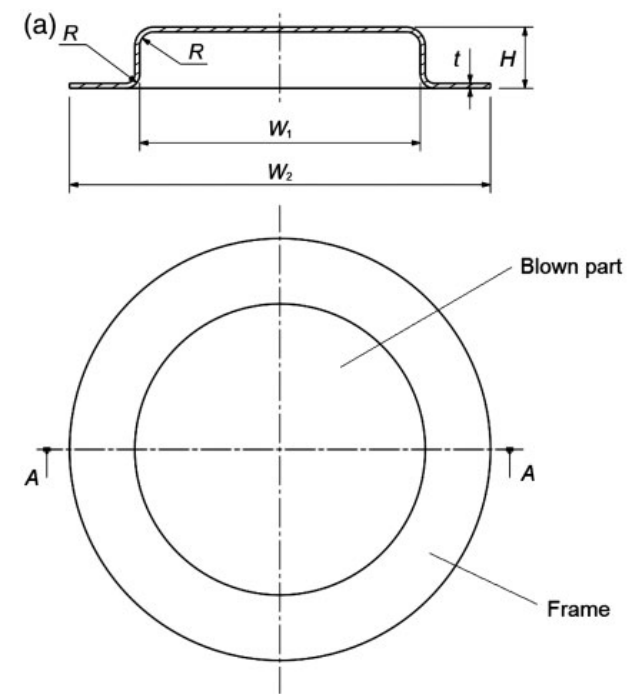

\section{Experimental study}

\section{Structure and material}

A proposed frangible composite canister cover was designed as a convex structure like a round cap, which was fabricated with a circumferential weak zone, as shown in Figure 1. The dimensions of the frangible cover are shown in Figure 1(a) and listed in Table 1. A blown part and a frame of the cover were adhesively bonded together along their edges to form a weak zone, which was lapped with multiple layers inside and outside, as shown in Figure 1(b), to improve the bonding strength of the cover. The height of lapped multiple layers was $h=h_{1}-h_{2}=5 \mathrm{~mm}$. The canister cover was designed in such a way that when subjected to an impulsive gas pressure, the adhesive bond between the blown part and the frame would break and the former would be blown away from the fixed frame. In the weak-zone structure, a right-triangle groove (the width of the groove was half of the wall thickness of the frangible cover, Figure 1(b)) was designed to improve the bonding strength and the pressure tightness of the frangible cover.

The material of the frangible composite canister cover under consideration was glass fabric/epoxy composites; the fabric was with a nominal ply thickness of

Table I. Dimensions of frangible cover (in $\mathrm{mm}$ ).

\begin{tabular}{llllllllll}
\hline Parameters & $W_{1}$ & $W_{2}$ & $R$ & $H$ & $t$ & $b$ & $t_{1}$ & $t_{2}$ & $h=h_{1}-h_{2}$ \\
\hline Magnitude & 200 & 300 & 10 & 40 & 3.5 & 50 & 0.1 & 0.2 & 5 \\
\hline
\end{tabular}

(b)

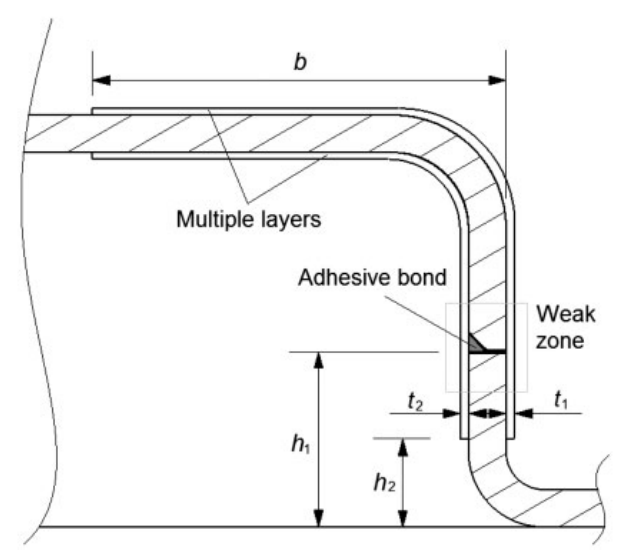

Figure I. Structure of circular frangible composite canister cover: (a) dimensions of frangible cover; (b) details of weak zone. 
$0.4 \mathrm{~mm}$. The glass fabric/epoxy plies were orthotropic, with the same in-plane Young's moduli of longitudinal and transverse directions $E_{1}$ and $E_{2}$. The material properties of the fabric/epoxy laminate are listed in Table 2. A number of frangible covers with a quasi-isotropic stacking sequence of $[(0 / 90) /( \pm 45)]_{2 s}$ were fabricated. The inside and outside multiple layers were lapped with glass fabric with a ply thickness of $0.1 \mathrm{~mm}$, with two plies employed inside and one outside.

\section{Manufacturing process}

A matrix material of the frangible composite cover was epoxy resin (E51 system, Brand 618). The cover was manufactured with a traditional manual lay-up process in laboratory with the following specific steps.

1. Under the condition of room temperature $\left(25^{\circ} \mathrm{C}\right)$, the mould was cleaned up and the low-temperature grease was daubed on the mould surface. According to the mould shape, polyester plastic film was cut and pasted on the mould.

2. The adhesive solution with epoxy resin, benzene dimethylamine and butyl phthalate was made and stirred evenly in accordance with weight proportion of 10:2:1.

3. The fabric layers with the ply sequence $[(0 / 90) /$ $( \pm 45)]_{2 \mathrm{~s}}$ were laid and soaked.

4. The adhesive solution was scraped evenly and then kept at room temperature for $24 \mathrm{~h}$.

5. The prefabrication was put in a heater incubator for $2 \mathrm{~h}$ at $50^{\circ} \mathrm{C}$ for aging treatment.

6. The prefabrication was taken out from the heater incubator and kept at room temperature for complete cooling (about $6 \mathrm{~h}$ ).

7. The cover was demoulded and the burrs were removed. The cover was divided into two parts at the position of the weak zone according to the design purpose by using mechanical cutting, and then a $45^{\circ}$ chamfer on the inside edge of the blown part was grinded.

Table 2. Properties of composite laminate.

\begin{tabular}{lrlr}
\hline Material constants & \multicolumn{3}{c}{$\begin{array}{l}\text { Strength } \\
\text { parameters }(\mathrm{MPa})\end{array}$} \\
\hline$E_{1}, E_{2}(\mathrm{GPa})$ & 21.50 & $X_{t}, Y_{t}$ & 385.42 \\
$E_{3}(\mathrm{GPa})$ & 5.68 & $Z_{t}$ & 62.35 \\
$G_{12}(\mathrm{GPa})$ & 3.42 & $X_{c}, Y_{c}$ & 279.36 \\
$G_{23}, G_{13}(\mathrm{GPa})$ & 2.13 & $Z_{c}$ & 234.26 \\
$v_{12}$ & 0.11 & $S_{12}$ & 68.50 \\
$V_{23}, V_{13}$ & 0.29 & $S_{23}, S_{31}$ & 44.31 \\
\hline
\end{tabular}

8. The frame and the blown part were assembled together with prime seam according to its original position, and $\mathrm{AB}$ adhesive solution (epoxy-resin system) was used for $30 \mathrm{~min}$ to fix this position. $\mathrm{AB}$ adhesive solution was injected in the triangle groove and kept at room temperature for $12 \mathrm{~h}$.

9. After curing, the inside surface was burnish and kept smooth. Multiple layers on both sides were pasted with epoxy-resin adhesive solution, and then kept at room temperature for $24 \mathrm{~h}$.

10. The cover was put in the heater incubator for $2 \mathrm{~h}$ at $50^{\circ} \mathrm{C}$ for aging treatment. The forming process of the cover was completed.

\section{Test procedures}

Based on the dimensions of the frangible cover, a simulated-launch test device was developed to emulate the gas flow imposed on the cover, as shown in Figure 2. The device consisted of a test tank, a gas pump, a pressure gage, a clamp ring, seal rings and bolts. The flange of the launch canister and the frame of the cover were matched and connected with a steel clamp ring and 12 bolts. The rubber seal rings were put among the steel clamp ring, the cover frame and the flange of the launch canister, with a function of sealing and protecting the cover to avoid effectively unwanted damage during the installation. The pressure loading on the frangible composite cover could be applied with the gas pump. Pressure data in the launch canister could be monitored in real time with the pressure gage.

The experimental process is shown in Figure 3. Five different heights of the weak-zone $\left(h_{1}=12 \mathrm{~mm}, 15 \mathrm{~mm}\right.$, $18 \mathrm{~mm}, 21 \mathrm{~mm}$ and $24 \mathrm{~mm}$ ) were used to provide different failure properties of the frangible cover. Three frangible composite covers were tested for every height of the weak zone. The generated deformations of the

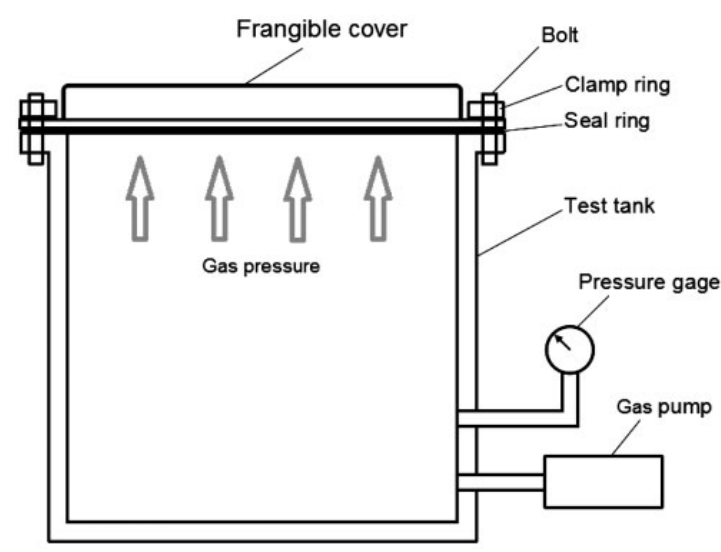

Figure 2. Simulated-launch test device. 
(a)

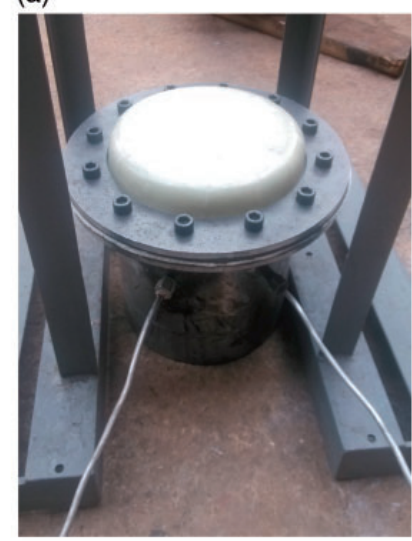

(c)

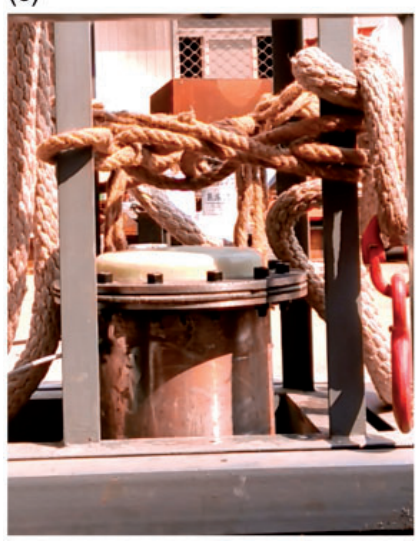

(b)

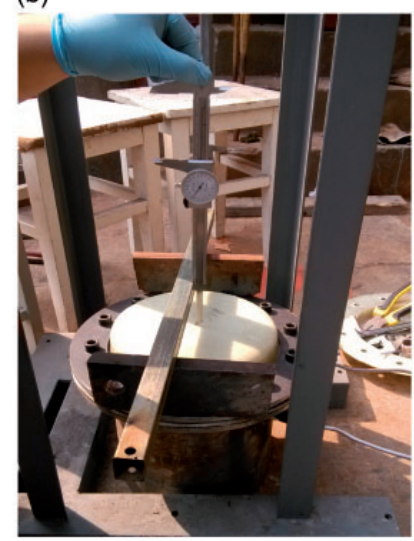

(e)

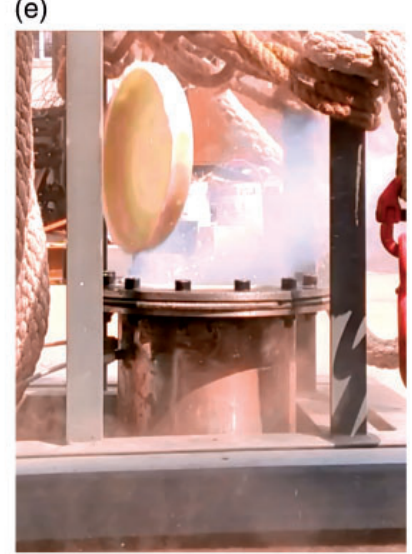

Figure 3. Experimental process for frangible cover: (a) before deformation test; (b) measuring deformation; (c) before destructive test; (d) localized flaw during loading process; (e) ultimate failure.

cover's centre along with the changes of pressure could be measured with a Vernier calliper (Figure 3(b)). The pressure load was applied at a rate of $2 \mathrm{kPa} / \mathrm{s}$. Note that record of deformation data was implemented every $0.05 \mathrm{MPa}$; it was stopped when the pressure load was $0.30 \mathrm{MPa}$ for safety. The structure was unloaded, and the measurements were repeated three times.

After the deformation tests, failure tests (Figure 3(c) to (e)) were carried out at a loading rate of $20 \mathrm{kPa} / \mathrm{s}$ using the gas pump to emulate the real process of launch until catastrophic failure. During the failure test, an elastic rope was attached to the steel test frame for protection. Soapy water was brushed around the frangible cover to show the local damage of the cover (see Figure 3(d)).

\section{TDM}

\section{Failure criteria}

In the failure analysis of the composite canister cover, the incipient failure in the cover structure was identified by using the phenomenological Tsai-Wu failure criterion ${ }^{19-21}$

$$
\begin{aligned}
& F_{1} \sigma_{1}+F_{2} \sigma_{2}+F_{3} \sigma_{3}+\mathrm{F}_{11} \sigma_{1}^{2}+\mathrm{F}_{22} \sigma_{2}^{2}+\mathrm{F}_{33} \sigma_{3}^{2}+\mathrm{F}_{44} \sigma_{4}^{2} \\
& \quad+\mathrm{F}_{55} \sigma_{5}^{2}+\mathrm{F}_{66} \sigma_{6}^{2}+2 F_{12} \sigma_{1} \sigma_{2}+2 F_{23} \sigma_{2} \sigma_{3} \\
& \quad+2 F_{31} \sigma_{3} \sigma_{1}=1
\end{aligned}
$$

with

$$
\begin{aligned}
& F_{1}=F_{2}=\frac{1}{X_{t}}-\frac{1}{X_{c}}, \quad F_{3}=\frac{1}{Z_{t}}-\frac{1}{Z_{c}}, \\
& F_{11}=F_{22}=\frac{1}{X_{t} X_{c}}, \quad F_{33}=\frac{1}{Z_{t} Z_{c}}, \\
& F_{44}=\frac{1}{S_{23}^{2}}, \quad F_{55}=\frac{1}{S_{31}^{2}}, \quad F_{66}=\frac{1}{S_{12}^{2}}, \\
& F_{12}=-\frac{1}{2} \sqrt{F_{11} F_{22}}, \quad F_{23}=-\frac{1}{2} \sqrt{F_{22} F_{33}}, \\
& F_{31}=-\frac{1}{2} \sqrt{F_{33} F_{11}}
\end{aligned}
$$

where $X_{t}, Z_{t}$ and $X_{c}, Z_{c}$ are the in-plane tensile and compressive strengths of the lamina; $S_{12}, S_{23}$ and $S_{31}$ are the in-plane shear strengths. On the other hand, in order to 
(a)

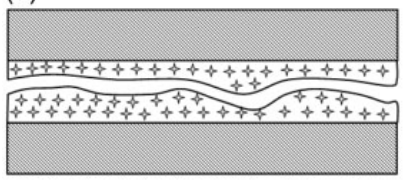

(b)

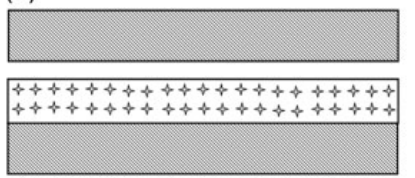

(c)

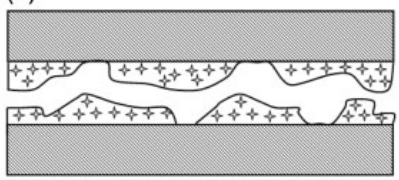

Figure 4. Failure modes of adhesively bonded joints: (a) cohesive failure; (b) interfacial debonding failure; (c) mixed failure.

Table 3. Properties of weak-zone in composite canister cover.

\begin{tabular}{lllllllll}
\hline Property & $E_{1}(\mathrm{GPa})$ & $E_{2}, E_{3}(\mathrm{GPa})$ & $G_{12}, G_{13}(\mathrm{GPa})$ & $G_{23}(\mathrm{GPa})$ & $v_{12}$ & $v_{23}, v_{13}$ & $\begin{array}{l}\text { Failure } \\
\text { tensile strain }\end{array}$ & $\begin{array}{l}\text { Failure } \\
\text { shear strain }\end{array}$ \\
\hline Magnitude & 6.94 & 3.72 & 3.53 & 3.42 & 0.14 & 0.29 & 0.021 & 0.011 \\
\hline
\end{tabular}

study a destruction path of the weak zone in the process of separation, the incipient failure in the weak zone was identified using the maximum strain failure criterion, stating that failure of the material is assumed to occur if any of the following conditions is satisfied

$$
|\varepsilon| \geq \varepsilon_{t} \text { or }|\gamma| \geq \gamma_{s}
$$

where $\varepsilon$ and $\gamma$ are the principal and shear strains; $\varepsilon_{t}$ and $\gamma_{s}$ are the failure tensile and shear strains of the weak zone.

Generally, the frangible cover failed at the weak zone and then the blown part flew away from the cover frame. The failure modes in the weak-zone structure were usually similar to three typical failure modes of adhesively bonded joints (Figure 4), accompanied by fracture or debonding of the multiple layers overlapped on two sides of the weak zone. In a simplified calculation, the multiple layers and the resin adhesive bond in the weak zone were equivalently converted into a new orthotropic material by using an average volume method, with the properties listed in Table 3. The failure strains of the weak zone were calculated with a static numerical model for an overlap joint extracted from the local structure of the weak zone. In the static numerical model, half of the frangible cover was selected to establish the analytical model due to symmetry. Symmetrical boundary condition and fixed constraints in the flange of the cover were adopted. Mean tested failure pressure of the cover obtained from the experiments was applied to the inner surface of the cover model. In static simulated results, the mean strains at the position of the weak zone (i.e. an overlap joint) were identified as failure strains in the TDM.

\section{Basic theory}

An approximate Riemann algorithm was used as an excellent method in analysis of gas and liquid flows, which is based on a Riemann solver of a finite volume element surface. ${ }^{16-18}$ A specific process of the approximate Riemann algorithm is based on decomposition of the problem into a discrete wave propagation process, in which superior performance and stability of the solution can be obtained by applying principles of the local Riemann solver at the element surface. The algorithm based on the Riemann solver of the element surface defines the flux of conservative physical quantities, such as mass, momentum and energy. By assuming that the motion of the gas flow is inviscid and it can be completely described by the Euler motion equation, the mass, momentum and energy conservation can be expressed as

$$
\frac{\partial q}{\partial t}+\frac{\partial f(q)}{\partial x}+\frac{\partial g(q)}{\partial y}+\frac{\partial h(q)}{\partial z}=0
$$

where $q$ is the state vector consisting of several conservative state variables, $f(q), g(q)$ and $h(q)$ represent conservative state variables, which are defined as

$$
\begin{gathered}
q=\left\{\begin{array}{l}
\rho \\
\rho u \\
\rho v \\
\rho w \\
E
\end{array}\right\}, \quad f(q)=\left\{\begin{array}{l}
\rho u \\
\rho u^{2}+P \\
\rho u v \\
\rho u w \\
(E+P) u
\end{array}\right\}, \\
g(q)=\left\{\begin{array}{l}
\rho w \\
\rho v \\
\rho v w \\
(E+P) v
\end{array}\right\}, \quad h(q)=\left\{\begin{array}{l}
\rho u w \\
\rho v w \\
\rho w^{2}+P \\
(E+P) w
\end{array}\right\}
\end{gathered}
$$

where $\rho$ is the material's density, $u, v$ and $w$ are three components of the velocity vector, $P$ is pressure and $E$ is the system energy. Gas flow, using the 
thermodynamic state equation of the ideal gas model, is expressed as

$$
P=(\gamma-1) \rho e
$$

where $e$ and $\gamma$ are the specific internal energy and specific heat ratio of the gas, respectively. $\gamma$ is the supposed constant over time in the analysis.

For the conservation equation (4), a spatial domain can be dispersed with an Euler unit grid. Applying the Gauss integral theorem to equation (4), its integral form becomes

$$
\frac{\partial}{\partial t} \int_{V} q d V+\int_{\partial V}\left(f(q) n_{x}+g(q) n_{y}+h(q) n_{z}\right) \mathrm{d} S=0
$$

Using the rotation invariance of the Euler's motion equation, this can be simplified to

$$
\frac{\partial}{\partial t} \int_{V} \tilde{q} \mathrm{~d} V+\int_{\partial V}(f(\tilde{q}) \mathrm{d} S=0
$$

where $\tilde{q}$ denotes the state vector. For each closed unit surface, equation (8) becomes a differential one-dimensional equation. In $1 \mathrm{D}$, this formula is

$$
\frac{\partial \tilde{q}}{\partial t}+\frac{\partial f(\tilde{q})}{\partial \tilde{x}}=0
$$

Considering that each element has adjacent elements to its left and right. Suppose the initial condition of flux $\tilde{q}$ as the following formula

$$
\tilde{q}(\tilde{x}, 0)= \begin{cases}\tilde{q}^{L} & \tilde{x}<0 \\ \tilde{q}^{R} & \tilde{x}>0\end{cases}
$$

where indices $L$ and $R$ denote left and right elements. Equations (8) and (9) describe the Riemann problem. Now, solving the general problem of the element surface simplifies to a local 1D Riemann problem according to the fluid state of left- and right-adjacent elements. A single flux can be determined by the flux function $f_{R}\left(q^{L}, q^{R}\right)$ and, on applying equations (7) to (9), one discrete equation can be obtained as follows

$$
\frac{d q_{i}}{d t}=-\frac{1}{V_{i}} \sum_{n=1}^{6} f_{R}\left(q^{L}, q^{R}\right) A_{n}
$$

where $i$ and $n$ denote the element number and element surface number, respectively; $V_{i}$ and $A_{n}$ are the element volume and the element surface area, respectively. Using the finite difference method, the flux function can be written as

$$
f_{R}\left(q^{L}, q^{R}\right)=\frac{1}{2}\left\{f\left(q^{L}\right)+f\left(q^{R}\right)\right\}-\frac{1}{2}\left\{\Delta f^{+}+\Delta f^{-}\right\}
$$

where

$$
\begin{aligned}
& \Delta f^{+}=f_{R}\left(q^{L}, q^{R}\right)-f\left(q^{L}\right) \\
& \Delta f^{-}=f\left(q^{R}\right)-f_{R}\left(q^{L}, q^{R}\right)
\end{aligned}
$$

Now, the flux function can be generalized to

$$
\begin{aligned}
f_{R}\left(q^{L}, q^{R}\right)= & \frac{1}{2}\left\{f\left(q^{L}\right)+f\left(q^{R}\right)\right. \\
& -\left[|\tilde{u}| \Delta q+(|\tilde{u}-\tilde{a}|-|\tilde{u}|) \tilde{\alpha}_{1} \tilde{R}_{1}\right. \\
& \left.+\left[+(|\tilde{u}+\tilde{a}|-|\tilde{u}|) \tilde{\alpha}_{2} \tilde{R}_{2}\right]\right\}
\end{aligned}
$$

Based on the state equation of ideal gas, the wave intensity can be expressed as

$$
\begin{aligned}
& \tilde{\alpha}_{1}=\frac{\Delta P-\tilde{\rho} \tilde{a} \Delta u}{2 \tilde{a}^{2}} \\
& \tilde{\alpha}_{2}=\frac{\Delta P+\tilde{\rho} \tilde{a} \Delta u}{2 \tilde{a}^{2}}
\end{aligned}
$$

The corresponding feature vectors are

$$
\begin{aligned}
& \tilde{R}_{1}=\left(\begin{array}{lllllll}
1 & \tilde{u}-\tilde{a} & \tilde{v} & \tilde{w} & \tilde{H}-\tilde{u} & \tilde{a}
\end{array}\right)^{T} \\
& \tilde{R}_{2}=\left(\begin{array}{lllllll}
1 & \tilde{u}+\tilde{a} & \tilde{v} & \tilde{w} & \tilde{H}+\tilde{u} & \tilde{a}
\end{array}\right)^{T}
\end{aligned}
$$

For all the variables, weighted averages can be obtained with the following formulae

$$
\begin{aligned}
& \tilde{\Phi}=\theta \Phi^{L}+(1-\theta) \Phi^{R} \\
& \theta=\frac{\sqrt{\rho^{L}}}{\sqrt{\rho^{L}+\sqrt{\rho^{R}}}}
\end{aligned}
$$

except for the weighted average of density

$$
\tilde{\rho}=\sqrt{\rho^{L}+\rho^{R}}
$$

The aforementioned method is called the approximate Riemann algorithm. The linearization process is used by application of the variable's weighted average on the element surface, which cannot meet the unequal range of entropy. Unequal entropy refers to the fact that system's entropy can only remain unchanged or increase. So, this method will lead to physical discontinuity. Accordingly, a fixed entropy method can be used to resolve this problem. The fixed entropy method can add some numerical viscosity or energy dissipation at the area of sonic points, shock waves and discontinuities. Energy dissipation is added only in the area where some feature vectors disappear. The fixed entropy method can be expressed in the 
following way

$$
\Psi(z)=\left\{\begin{array}{cc}
|z| & |z| \geq \delta_{1} \\
\frac{\left(z^{2}+\delta_{1}^{2}\right)}{2 \delta_{1}} & |z|<\delta_{1}
\end{array}\right.
$$

where

$$
\delta_{1}=\delta\left(\left|\frac{\tilde{u}}{\tilde{a}}\right|+\left|\frac{\tilde{v}}{\tilde{\tilde{a}}}\right|+\left|\frac{\tilde{w}}{\tilde{a}}\right|+1\right)
$$

In this paper, a fluid-solid interaction is considered when the gas flow impacts on the frangible cover. During this dynamic process, a Lagrange grid of the frangible cover interacts with the Euler grid of the gas flow. This interaction can be achieved by employing a mutual coupling interface, which is also the flow field boundary of the Euler grid. Simultaneously, the material in the Euler grid generates a force on the interface, resulting in deformation of the Lagrange grid. This is called 'General Coupling' in the fluid-solid interaction problem.

\section{FE model}

The process of separation of the frangible composite canister cover was studied by using transient-dynamics software MSC.Dytran, which can analyse the nonlinear dynamic behaviour of structures and fluid materials. The approximate Riemann algorithm with second-order accuracy in MSC.Dytran was used to

Table 4. Parameters of explosive gas ball.

\begin{tabular}{llll}
\hline Parameter & Radius $(\mathrm{mm})$ & $\begin{array}{l}\text { Distance to the } \\
\text { cover }(\mathrm{mm})\end{array}$ & $\begin{array}{l}\text { Density } \\
\left(\mathrm{g} / \mathrm{mm}^{3}\right)\end{array}$ \\
\hline Magnitude & 10 & 250 & $2.5 \times 10^{-5}$ \\
\hline
\end{tabular}
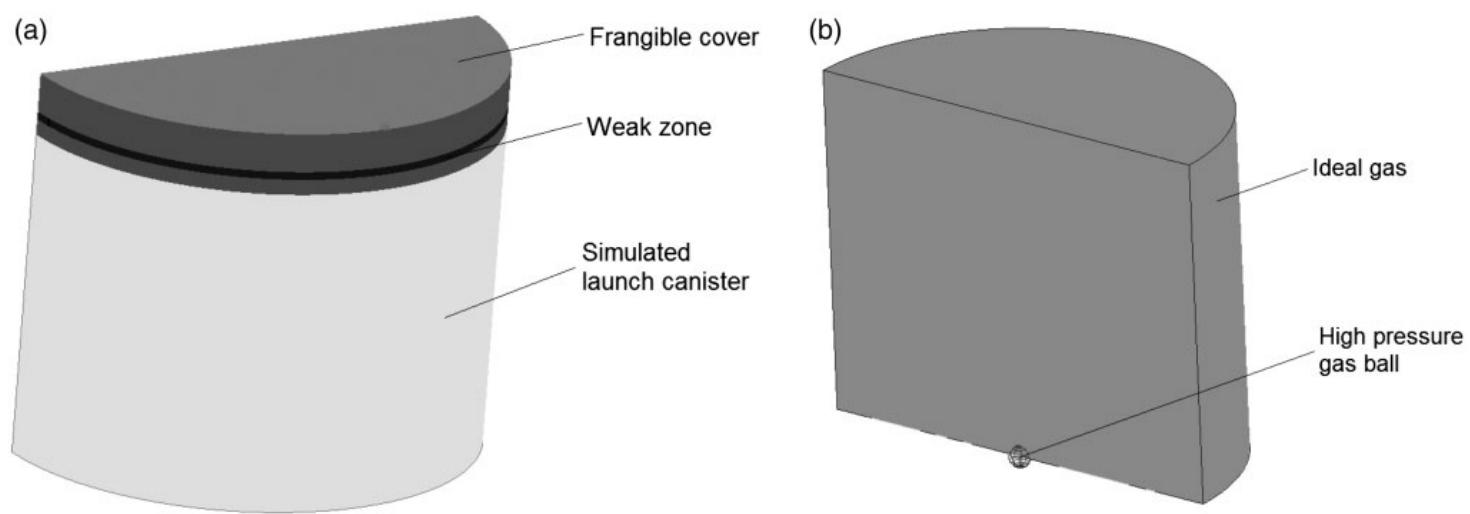

calculate the effect of fluid-solid coupling between the gas flow and the composite canister cover.

A gas flow in the missile launch is a mixture of air and rocket fuel gas with high temperature. In this paper, to simply the analysis, the characteristics of pressure distribution in the compressible gas flow to the canister cover were mainly considered neglecting the effect of high temperature. Compared with atmospheric environment, the gas flow from the missile engine was considered as the gas with high temperature and high pressure, expanding rapidly from the bottom of the launch canister and then developing an expansion wave in the sealed space, finally impacting the canister cover in the form of a spherical wave. So, in numerical modelling, the gas flow can be considered to generate and develop from an explosive gas ball with high pressure. Parameters of the explosive gas ball are listed in Table 4.

A real-time area of gas leakage was difficult to simulate accurately during the process of separation. So the weak-zone of the cover was defined as the approximate surface of gas leakage. The failure of coupling surface between the weak zone and gas was defined with the COUP1FL card in MSC.Dytran. When the coupling part fails, the corresponding unit is deleted, and then a new porous coupling surface is generated automatically, with the explosive gas leaking through it. Generally, the coupling surface should be closed. So, a dummy element (DE) was established on the symmetry plane in a half-canister-cover model to satisfy this requirement. A 3D FE model for the cover and the simulated launch system is shown in Figure 5, where the Lagrange grid is used for the discrete models of the cover and the simulated launch device while the Euler grid for the ideal gas (or air). The flanges of the cover and the simulated launch device were discarded in the simplified model. Symmetry boundary condition was adopted to improve the constraints of the model, and the clamped constraints were

Figure 5. Transient-dynamics model: (a) Lagrange part; (b) Euler part. 
(a)

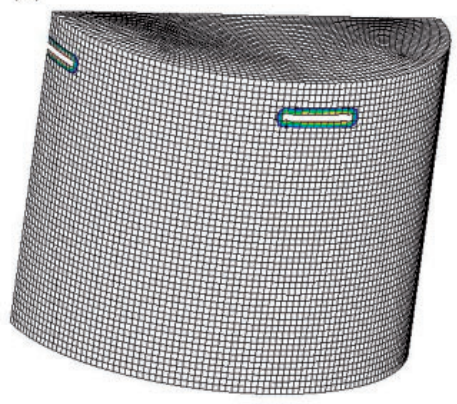

(b)

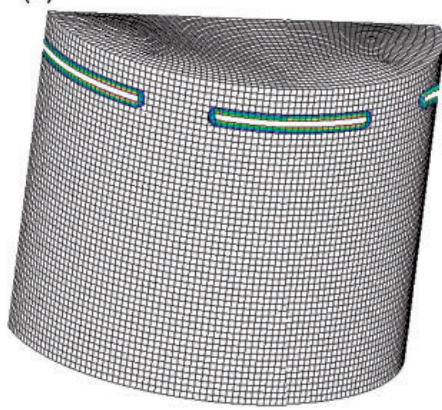

(c)

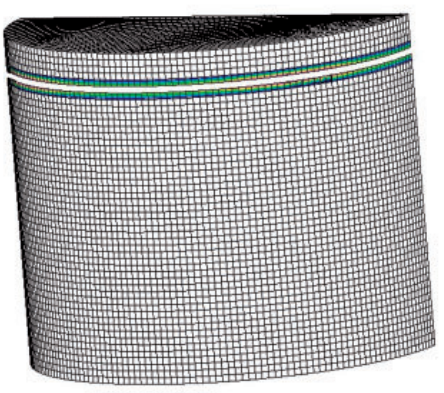

Figure 6. Simulated failure process of frangible composite cover with weak-zone height $h_{1}=18 \mathrm{~mm}$ : (a) $\mathrm{t}=15.2 \mathrm{~ms}$; (b) $\mathrm{t}=15.5 \mathrm{~ms}$; (c) $\mathrm{t}=15.6 \mathrm{~ms}$.

imposed on the bottom surface of the simulated launch system.

The modelled failure process in the frangible composite cover with the weak-zone height of $18 \mathrm{~mm}$ is illustrated in Figure 6. An initial crack started at the weak-zone from about $15.0 \mathrm{~ms}$ and extended around the frangible cover in the simulated failure process. The weak-zone failed completely at $15.6 \mathrm{~ms}$ (Figure 6(c)), and the whole failure process lasted for only about $0.6 \mathrm{~ms}$. The incipient and ultimate failure of the frangible cover happened obviously at the weak-zone structure. At failure, the corresponding elements in the weak zone were deleted during the computational process in the TDM, which visually displayed the separation process between the blown part and the cover frame. The frangible composite canister covers with other weak-zone heights (i.e. $h_{1}=12 \mathrm{~mm}, 15 \mathrm{~mm}, 21 \mathrm{~mm}$ and $24 \mathrm{~mm}$ ) showed the similar features as the aforementioned cover $\left(h_{1}=18 \mathrm{~mm}\right)$ in the TDM.

\section{Results and discussion}

In order to understand the deformation and failure properties of the frangible composite cover, the TDM was used to perform the FE analysis of the tested covers. The 3D FE model for the cover including the blown part, the adhesive bond weak-zone and the frame was established for nonlinear dynamic analysis as well as for simulation of the launch system. In this section, deformations of the cover's centre and failure pressures obtained with the TDM are discussed in comparison with the experimental results.

\section{Deformation of cover's centre}

Deformations of the cover's centre were calculated with the TDM; the results are shown in Figure 7 in comparison with the experimental results. Due to the fact that the frangible cover works under specific pressure before the missile is launched, deformation of the cover's centre (maximum deformation of the whole cover) should be concerned during its design and placement process. There are some differences in deformations of the cover's centre for different weak-zone heights $\left(h_{1}\right)$. At internal pressure of $0.30 \mathrm{MPa}$, mean deformations of the cover's centre in tests were $6.02 \mathrm{~mm}\left(h_{1}=12 \mathrm{~mm}\right)$, $6.33 \mathrm{~mm}\left(h_{1}=15 \mathrm{~mm}\right), 6.24 \mathrm{~mm}\left(h_{1}=18 \mathrm{~mm}\right), 6.44 \mathrm{~mm}$ $\left(h_{1}=21 \mathrm{~mm}\right)$ and $6.47 \mathrm{~mm}\left(h_{1}=24 \mathrm{~mm}\right)$, respectively. The results indicate that the deformation of cover's centre mainly depends on the primary cover structure rather than the weak-zone location. It is noted that the differences $[=(\mathrm{TDM}-$ Expt. $) /$ Expt.] between the numerical and experimental results were in the range from $10.9 \%\left(h_{1}=15 \mathrm{~mm}\right)$ to $16.1 \% \quad\left(h_{1}=12 \mathrm{~mm}\right)$, as shown in Figure 7(a) to (e). All the numerical results are higher than experimental ones in five analysed cases, which may be caused by uncertainties involved in the fabrication process and variations in the material properties. Still, good agreements between numerical and experimental results can validate the suitability of the proposed TDM for deformation analysis of the frangible composite cover.

It is also noted that evolution of cover's centre deformations with pressure was non-linear both in numerical and experimental results. The quadratic polynomial fitting curves for the experimental data in the five analyzed cases are also shown in Figure 7; they have the following form

$$
y=A x^{2}+B x
$$

where $A$ and $B$ are the quadratic and monomial fitting coefficients, respectively, listed in Table 5. The correlation coefficients fall in the range from 0.9986 to 0.9990, demonstrating remarkable fitting results for cover centre deformations using quadratic polynomial in the pressure loading range up to $0.30 \mathrm{MPa}$. 

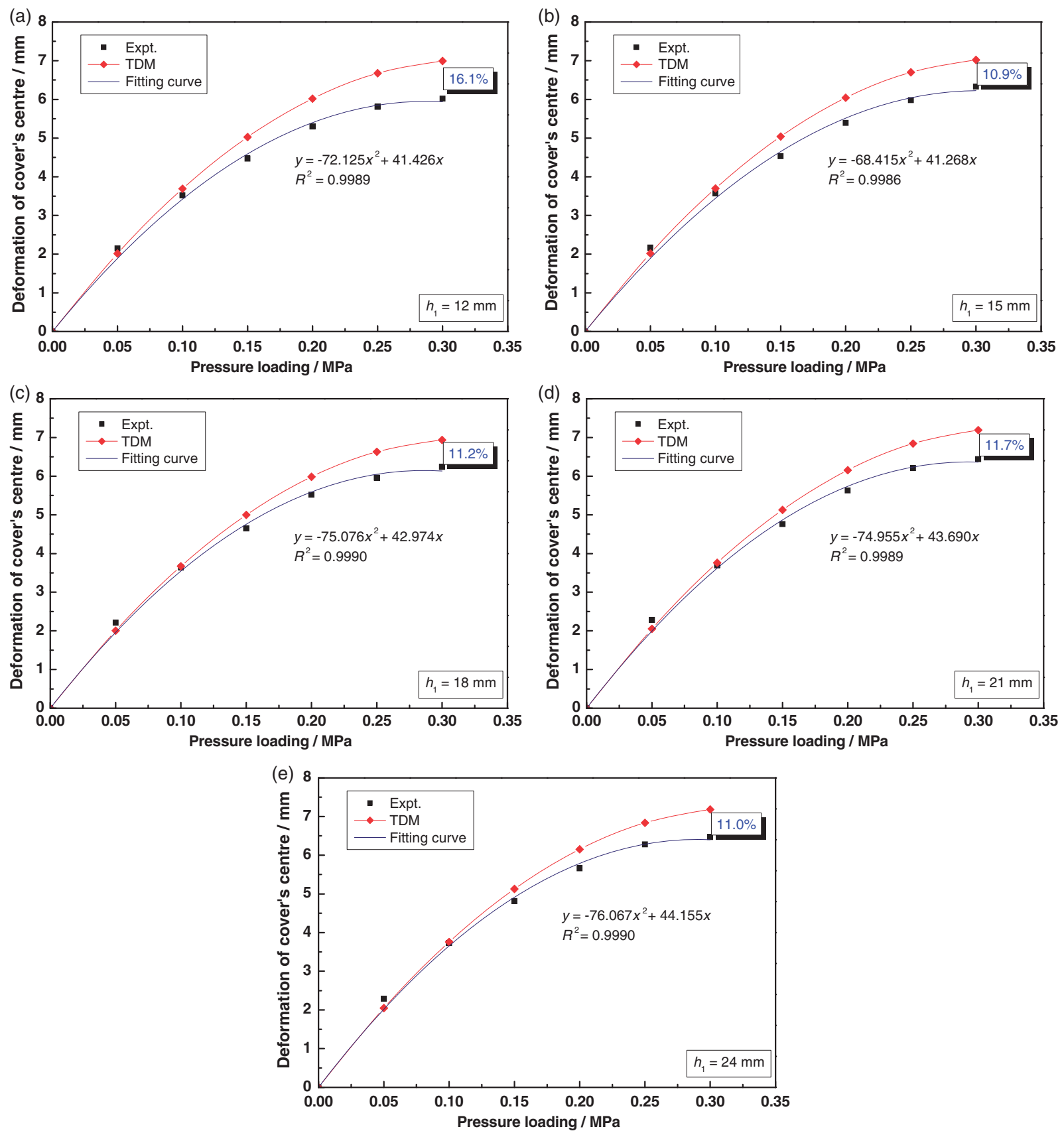

Figure 7. Effect of pressure on deformation of cover's centre for different weak-zone heights $h_{1}$ : (a) $12 \mathrm{~mm}$; (b) $15 \mathrm{~mm}$; (c) $18 \mathrm{~mm}$; (d) $21 \mathrm{~mm}$; (e) $24 \mathrm{~mm}$.

\section{Failure pressure}

The suggested numerical method was also used to predict to failure pressures of frangible covers with different weak-zone heights. The calculated levels of failure pressures are shown in Figure 8 in comparison with the experimental results. Failure pressures of the frangible covers observed in the TDM increased first and then decreased, basically being consistent with the experimental results. The trend for the mean experimental failure pressure with the weak-zone heights can be described with a quadratic polynomial (Figure 8), with the squared correlation coefficient of 0.9637 . The minimum and maximum values of experimental failure pressures of the frangible covers were $0.54 \mathrm{MPa}$ (corresponding to $\left.h_{1}=12 \mathrm{~mm}\right)$ and $0.79 \mathrm{MPa}\left(h_{1}=18 \mathrm{~mm}\right)$. Notably, the numerical results were again higher than the experimental data, with the differences $[=(\mathrm{TDM}-$ Expt.)/Expt.] from $8.2 \%$ at $h_{1}=21 \mathrm{~mm}$ to $11.5 \%$ at $h_{1}=24 \mathrm{~mm}$. The main cause of these differences is the 
Table 5. Comparison of coefficients of deformation fitting curves of cover's centre with different weak-zone heights.

\begin{tabular}{|c|c|c|c|}
\hline \multirow{2}{*}{$\begin{array}{l}\text { Weak-zone } \\
\text { height } h_{1}(\mathrm{~mm})\end{array}$} & \multicolumn{2}{|c|}{ Fitting coefficients } & \multirow{2}{*}{$\begin{array}{l}\text { Correlation } \\
\text { coefficient } R^{2}\end{array}$} \\
\hline & $A\left(\mathrm{~mm} / \mathrm{MPa}^{2}\right)$ & $B(\mathrm{~mm} / \mathrm{MPa})$ & \\
\hline 12 & -72.125 & 41.426 & 0.9989 \\
\hline 15 & -68.415 & 41.268 & 0.9986 \\
\hline 18 & -75.076 & 42.974 & 0.9990 \\
\hline 21 & -74.955 & 43.690 & 0.9989 \\
\hline 24 & -76.067 & 44.155 & 0.9990 \\
\hline
\end{tabular}

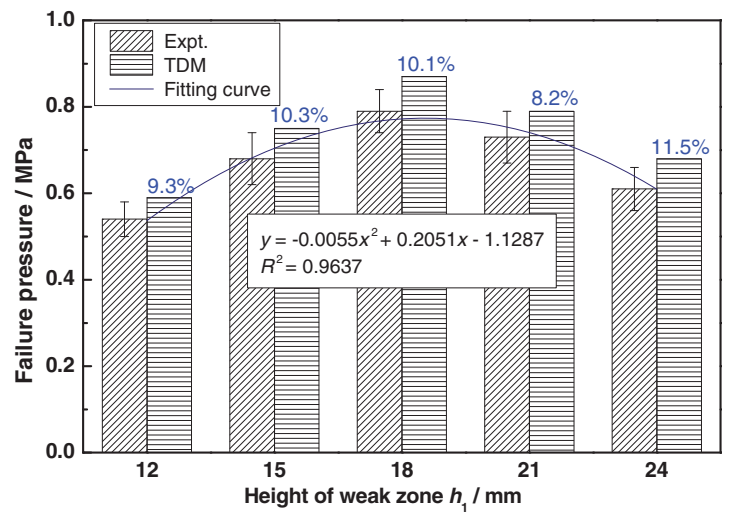

Figure 8. Failure pressure of frangible composite cover for different weak-zone heights.

same as mentioned in deformation of cover's centre section. In view of the results in Figure 8, it should be noted that the height of weak-zone had a significant effect on failure pressure of the frangible cover. With the same weak-zone structure, the increase in the weakzone height caused a non-monotonic evolution of failure pressure of the frangible cover that rose first and then reduced, achieving a peak value at $h_{1}=18 \mathrm{~mm}$. The main cause of this phenomenon may be that the stresses (or strains) in the cover's side wall are distributed with a non-monotonic gradient field from bottom to top due to the cap structure of the cover. It can be considered as a reference for design of the frangible composite cover with specific failure pressures.

\section{Conclusion}

A TDM for analysis of the mechanical behaviour of the frangible composite canister cover was proposed. The instantaneous separation process was simulated using the TDM-based FE model. Deformation of the cover's centre and failure pressure of the frangible cover were determined for five different weak-zone heights using numerical simulation in comparison with the experimental results. The manufacturing process of the frangible cover using a traditional manual lay-up method was implemented followed by the experimental investigation of deformation of the cover's centre under pressure load and failure pressure of the cover.

The study demonstrated that deformations increased following a quadratic polynomial trend in the pressure range up to $0.30 \mathrm{MPa}$; nearly identical deformations of the cover's centre with the increasing pressure in the frangible covers with different weak-zone heights were observed. Deformation of the cover's centre depends mainly on the primary cover structure rather than the weak-zone location. It was also shown that the height of the weak zone has an important effect on failure pressure of the frangible cover. Magnitudes of this pressure obtained in numerical and experimental results first increased and then decreased with the increasing weak-zone height; a quadratic polynomial trend of this process was quantified.

The close agreements between numerical and experimental results can validate suitability of the proposed TDM for both deformation and failure analysis of the frangible composite canister cover with different weakzone heights. Furthermore, the material properties used in simulations of mechanical behaviour of the frangible cover and the failure criteria in predicting failure of the cover are reasonable and acceptable for design and optimisation.

\section{Declaration of Conflicting Interests}

The author(s) declared no potential conflicts of interest with respect to the research, authorship, and/or publication of this article.

\section{Funding}

The author(s) disclosed receipt of the following financial support for the research, authorship, and/or publication of this article: This work was supported by the National Natural Science Foundation of China (Grant No. 11503093), the Fundamental Research Funds for the Central Universities, the Priority Academic Program Development of Jiangsu Higher Education Institutions (PAPD) and the Funding of Jiangsu Innovation Program for Graduate Education (Grant No. KYLX_0222).

\section{References}

1. Krol UB. Frangible cover assembly for missile launchers. U.S. Patent, No. 3742814, USA, 1973.

2. Beeler DR, Chase VA, Copeland RL, et al. Protective cover for a missile nose cone. U.S. Patent, No. 3970006, USA, 1976.

3. Boeglin PH and Chigot CR. Plate-glass fitted with an explosion-cutting device. U.S. Patent, No. 4333381, USA, 1982.

4. Bell RE and Reid W JT. Missile weapon system. U.S. Patent, No. 5239909, USA, 1993. 
5. Doane WJ. Frangible fly through diaphragm for missile launch canister. US Patent, No. 4498368, USA, 1985.

6. Kam TY, Wu JH and Wang WT. External failure pressure of a frangible laminated composite canister cover. Compos Struct 1999; 47: 563-569.

7. Wu JH, Wang WT and Kam TY. Failure analysis of a frangible laminated composite canister cover. Proc Instit Mech Eng Part G: J Aerosp Eng 1999; 213: 187-195.

8. Kam TY and Jan TB. First-ply failure analysis of laminated composite plates based on the layerwise linear displacement theory. Compos Struct 1995; 32: 583-591.

9. Kam TY, Sher HF, Chao TN, et al. Predictions of deflection and first-ply failure load of thin laminated composite plates via the finite element approach. Int J Solids Struct 1996; 33: 375-398.

10. Kam TY, Liu YW and Lee FT. First-ply failure strength of laminated composite pressure vessels. Compos Struct 1997; 38: 65-70.

11. Kam TY and Chang ES. Reliability formulation for composite laminates subjected to first-ply failure. Compos Struct 1997; 38: 447-452.

12. Kam TY and Lai FM. Experimental and theoretical predictions of first-ply failure strength of laminated composite plates. Int J Solids Struct 1999; 36: 2379-2395.

13. Cao R, Zhou G, Cai D, et al. Parametric design and experimental study for weak area structure of circle composite fragile cover. 2014 International Conference on Mechanics and Civil Engineering (ICMCE-14). Adv Eng Res 2015; 7: 49-56.
14. Cai D, Zhou G, Wang X, et al. Molding process and experimental research on a circular composite fragile cover. 2015 International Conference on Intelligent Systems Research and Mechatronics Engineering (ISRME 2015). Adv Intell Syst Res 2015; 121: 1677-1681.

15. Zeng $\mathrm{W}$ and Jiang $\mathrm{Y}$. Failure analysis of a composite frangible cover based on transient dynamics. Appl Mech Mater 2013; 395: 55-59.

16. Roe PL. Approximate Riemann solvers, parameter vectors, and difference schemes. J Comput Phys 1981; 43: 357-372.

17. Rumsey CL, Van Leer B and Roe PL. A grid-independent approximate Riemann solver with applications to the Euler and Navier-Stokes equations. In: 29th Aerospace sciences meeting, Reno, NV, 7-10 January 1991, pp.1-12. Washington, D.C.: AIAA 91-0239.

18. Glaister P. An approximate linearised Riemann solver for the Euler equations for real gases. J Comput Phys 1988; 74: $382-408$.

19. Tsai SW and Wu EM. A general theory of strength for anisotropic materials. J Compos Mater 1971; 5: 58-80.

20. Leong M, Overgaard LC, Daniel IM, et al. Interlaminar/ interfiber failure of unidirectional glass fiber reinforced composites used for wind turbine blades. J Compos Mater 2013; 47: 353-368.

21. Koc M, Sonmez FO, Ersoy N, et al. Failure behavior of composite laminates under four-point bending. J Compos Mater 2016, doi: 10.1177/0021998315624251. 